\title{
"BUENOSTIAMO PRATICANDO": ANÁLISE \\ COMPARATIVA DOS SINAIS DISCURSIVOS \\ UTILIZADOS EM SITUAÇÕES INTERATIVAS ENTRE \\ APRENDIZES DE LÍNGUAS PRÓXIMAS
}

\section{"BUENO STIAMO PRATICANDO": COMPARATIVE ANALYSES OF DISCOURSE MARKERS USED IN INTERACTIVE CONTEXTS AMONG SIMILAR LANGUAGES}

\author{
Roberta Ferroni* \\ Marilisa Birello
}

\section{RESUMO}

Este artigo compara os sinais discursivos utilizados em contextos interativos entre aprendizes de italiano como língua estrangeira, cuja língua materna é o português brasileiro e o catalão-espanhol. Comparando-se os dois corpora, emerge que os marcadores discursivos podem ser expressos não somente na LE, mas também por meio da LM. A categoria dos marcadores interativos mais frequentes é aquela dos fatismos e dos mecanismos de aprovação, ao passo que os marcadores metatextuais são totalmente ausentes. Quando os marcadores discursivos são expressos em LM, é frequente a ausência de atividades de negociação, porque prevalece nos interactantes o desejo de levar a termo a tarefa que lhes foi atribuída.

Palavras-chave: marcadores discursivos; línguas afins; estratégias de negociação.

\section{ABSTRACT}

The paper compares the discursive markers used in interactive contexts among learners of Italian as a foreign language (henceforth FL) whose mother tongue is either Brazilian Portuguese or Spanish and Catalan. Comparing the two corpora it emerges that discursive markers can be expressed in both the FL as in the L1. The most widely used category of interactive markers is that of phatic expressions and approval mechanisms, while metatextual markers are completely absent. When discursive markers are expressed in L1 there is a lack of interactive negotiation, since speakers prefer to engage the task assigned.

Keywords: discoursive markers; similar languages; negotiation strategies.

\footnotetext{
* Universidade de São Paulo - USP, São Paulo (SP), Brasil. robertaferronibr@gmail.com; Universitat Autònoma de Barcelona - UAB, Barcelona, Espanha.marilisa.birello@gmail.com
} 


\section{INTRODUÇÃO}

A presente contribuição, de tipo descritivo, tem o propósito de analisar de que maneira os aprendizes de italiano (doravante I) utilizam, no decorrer das interações entre pares, um conjunto de sinais discursivos (doravante SD), entendido aqui, como salientam os estudos da conversação, como elementos que, "esvaziando-se em parte de seu sentido originário, adquirem valores acrescidos e servem para destacar a estruturação do discurso, coligar elementos frasais, interfrasais, extrafrasais e explicitar a colocação do enunciado em uma dimensão interpessoal, salientando a estrutura interativa da conversação" (BAZZANELLA, 2006, p.455, tradução nossa). O estudo é realizado por meio da análise de dois corpora levantados entre estudantes de italiano língua estrangeira (doravante LE) e empenhados na realização de atividades interativas, cuja língua materna (doravante LM) é afim à LE: o português brasileiro (doravante $\mathrm{PB}$ ), no primeiro caso e o catalão e o espanhol (doravante CS), no segundo. O curso era ministrado, em um caso, por um professor italiano; no outro, por um professor catalão com formação na Itália. O fato de um dos dois docentes ser italiano e o outro catalão, mas com excelente conhecimento da língua italiana, permitiu que fizéssemos uma comparação entre os usos das línguas presentes na aula. Essa diferença, embora não seja objeto de estudo deste trabalho, foi levada em conta no esboço da pesquisa porque pode ser significativa em relação ao emprego e ao tratamento dos SD na aula.

Escolhemos analisar as atividades interativas entre pares já que é no decorrer delas que se concentra o número maior de SD (ver abaixo, seção "Metodologia").

Partindo dos pressupostos de que os SD, em decorrência de sua fragilidade semântica, são palavras "vazias" cujo emprego adequado é difícil de apreender (PUGLIESE, 2015), mesmo em contextos de aprendizagem facilitados ${ }^{1}$, formulamos a hipótese de que o comportamento dos aprendizes de italiano LE com LM afins possam apresentar algumas convergências no tocante ao uso dos SD em situações interativas.

Em especial, os objetivos que nos propomos são:

- identificar as formas e as funções que desempenham os SD em ambos os corpora; - verificar por meio de que língua são expressos os SD por aprendizes cuja LM é próxima da LE;

\footnotetext{
1 A aprendizagem de línguas afins é mais rápida porque os falantes dessas línguas têm condição de compreender o sentido global de um texto escrito (e, em medida menor, de um texto oral) em uma língua próxima sem nunca tê-la praticado ou estudado (MORDENTE; FERRONI, 2015).
} 
- verificar, quando são expressos em LM, se estimulam ou não um conjunto de estratégias como negociações, reformulações, auto e heterorreformulação que podem contribuir para o desenvolvimento do sistema interlinguístico e, portanto, para a aquisição/aprendizagem da LE;

- verificar se os comportamentos dos aprendizes de italiano LE, língua afim ao PB e ao CS, convergem ou divergem no tocante ao uso dos $\mathrm{SD}$ em um contexto interativo.

Pensamos que um trabalho crítico sobre o uso dos SD presentes no discurso dos aprendizes possa ajudar a compreender de maneira mais rigorosa as dificuldades que os interactantes irão encontrar no decorrer do processo de aquisição/ aprendizagem de uma LE próxima da sua própria e a comunicação que se instaura na aula de LE, lugar social especial, em que a conversação oscila entre modalidades exolíngues, caracterizadas pela divergência entre os repertórios linguísticos dos interactantes e a comunicação bilíngue, que apresenta o uso simultâneo das duas línguas que estão frente a frente (ALBERT; PY, 1986; LÜDI; PY, 1986).

Esperamos que esse tipo de observação possa fornecer um suporte válido para preencher uma lacuna que existe entre a fase de programação de um curso e de planejamento dos objetivos e ações didáticas e o resultado final, ou seja, o produto da instrução.

Devido à complexidade e à multiplicidade de fatores que determinam o nosso objeto de estudo, o posicionamento metodológico adotado para a discussão dos dados não poderia deixar de ser híbrido, interpretando estudos vários, desde a didática, passando por disciplinas como a sociolinguística e a etnografia e a pragmática, em função de uma vontade de maximizar a nossa capacidade de interpretação do que se passa na aula de LE.

Esses instrumentos teóricos nos auxiliarão a evidenciar os modelos de construção do discurso colaborativo e as modalidades de resolução dos problemas que se apresentam no decorrer da comunicação quando a interação ocorre em contextos exolíngues.

\section{A INTERAÇÃO ENTRE PARES EM UM CONTEXTO FAVORÁVEL AO ESTUDO DOS MARCADORES DISCURSIVOS}

Dado que quando se estuda a análise dos SD é necessário levar em conta variáveis da comunicação em andamento, que podem estar relacionadas tanto ao "contexto situacional", ou seja, a todos os elementos da situação em que a 
comunicação acontece, quanto ao "contexto linguístico", ou seja, a todos os elementos linguísticos de que o texto faz parte (BAZZANELLA, 2006, p. 452), nessa parte vamos descrever a estrutura interativa e o tipo de atividades que os aprendizes estavam realizando.

A comunicação verbal que acontece normalmente na aula, inclusive na aula de LE, é composta de interações de tipo diferente, sendo que algumas são mais estruturadas e codificadas nos papéis, como, por exemplo, a aula frontal ${ }^{2}$; outras, ao contrário, estão mais próximas da conversação entre pares, como, por exemplo, o trabalho em duplas ou em grupos pequenos.

Esse último tipo de interação é um terreno muito fértil para o estudo dos SD porque, como observa Bazzanella (2006), os SD são muito mais frequentes na fala dialógica, em situação informal, pouco controlada, do que em situações formais (em que o controle por parte do falante é maior) ${ }^{3}$. Por essa razão, preferimos analisar sequências dialógicas extraídas de um contexto em que as duplas de estudantes estavam ocupadas em a realizar atividades que têm como objetivo desenvolver a interação e a negociação.

Cazden (1988) e Hall (1995), dentre outros, estudando a estrutura comunicativa que caracteriza a maior parte das trocas entre professor e aluno durante a aula, chamada Iniciação-Resposta-Avaliação (IRA), destacam que uma rotina desse tipo não oferece aos estudantes a oportunidade de desenvolverem o complexo saber interacional, linguístico e cognitivo exigido pela conversação ordinária. Com efeito, a pergunta pode ter aspectos que bloqueiam a comunicação ou, no mínimo, que a fixam dentro de alguns esquemas. Os argumentos do discurso e sua organização são gerenciados por um único participante e não refletem a curiosidade e a necessidade de aprofundamento que afloraram no decorrer das trocas verbais (FASULO;

2 Para Van Lier (1988) e Castro (1989), é possível identificar três grandes tradições que estudam a interação na aula de língua: a abordagem funcional (SINCLAIR, COULTHARD, 1975) detém-se no sentido das interações e destaca a rotina que as constituem; a abordagem etnometodológica, típica da etnometodologia e da análise da conversação, descreve as regras que subjazem à "sintaxe da conversação" (SCHEGLOFF, 1979, tradução nossa) e os pesquisadores que atuam nesse setor observam os mecanismos do discurso: as duplas adjacentes, os turnos de palavra, os reparos (MEHAN, 1979; ORLETTI, 2000; FASULO; GIRARDET, 2002); a abordagem etnográfica, representada por um conjunto muito eclético de estudos do discurso, visa levantar os limites e os defeitos da estrutura do processo interacional a fim de promover entre os sujeitos envolvidos, nesse caso os professores, espaços de autoanálise e de reflexão mediante a observação de dados interrelacionais transcritos, no intuito de melhorar as condições da interação (BANGE, 1996; GRIGGS, 1998; CAMBRA, 2003; PEKAREK, 2002).

3 Como observam Fasulo \& Girardet (2002), o diálogo dirigido pelo professor visa atingir o ideal do discurso planejado, uma vez que valoriza a formulação cuidadosa e peremptória mais do que momentos informais de elaboração e de experiência de compreensão. 
GIRARDET, 2002). A esse respeito, Bange (1996) comenta que a sequência IRA instaura uma comunicação totalmente diferente da conversação ordinária, porque a passagem para a unidade sucessiva depende exclusivamente da avaliação que o professor fará da dupla anterior, ao passo que, na conversação, os turnos de palavra se sucedem reciprocamente. Portanto, uma avaliação negativa irá produzir uma parada na progressão e acionará um movimento de retomada de elementos da dupla anterior, sobre a qual será efetuada a avaliação.

É preciso observar, entretanto, que uma rotina desse tipo reduz drasticamente a conversação a simples operação de correção gramatical, na qual o terceiro movimento, aquele iniciado pelo professor, consiste, na maioria dos casos, em reformular problemas de natureza formal (BANGE, 1996; PEKAREK, 2002; CAMBRA, 2003). Por causa disso, o aprendiz, no intuito de evitar os erros, tende a adotar "estratégias de evitamento" (GRIGGS, 1998, tradução nossa), reduzindo, assim, drasticamente sua responsabilidade discursiva (PEKAREK, 2002; CAMBRA, 2003).

Dos estudos de matriz etnográfica que analisam as modalidades de interação que acontecem em grupos compostos por pares emerge que essa interação adquire características totalmente diferentes quando os alunos não são controlados pelo professor (BANGE, 1996; GRIGGS, 1998; PEKAREK, 2002; CAMBRA, 2003; BIRELLO, 2005; FERRONI, 2013). Observou-se, por exemplo, que, graças ao status a priori igualitário, instaura-se uma ordem interacional na qual todos os membros gozam dos mesmos direitos e deveres conversacionais. Tanto isso é verdade que a assunção do turno da fala acontece mais por meio da autosseleção que da heterosseleção (CAMBRA, 2003). Não haverá nem interlocutores muito calados nem sobreposições nem uma excessiva "incontinência verbal" (CAMBRA, p. 76, tradução nossa).

O trabalho em duplas ou em pequenos grupos oferece a possibilidade de participar de atividades comunicativas semelhantes àquelas que acontecem em contextos naturais. Os estudantes, trabalhando em conjunto, sentem-se mais à vontade, dado que não estão sujeitos a uma eventual avaliação do professor. Bygate (1988) afirma que o insumo produzido pelo professor não é suficiente para a aprendizagem e que, ao contrário, é na interação com seus próprios colegas que o aprendiz se sente na obrigação de elaborar frases que tenham sentido e aprende a utilizar as características típicas do discurso falado. Segundo Barnes e Todd (1977), os alunos se empenham mais quando falam sem a presença do professor e têm possibilidade de assumir uma posição mais ativa e independente no tocante aos seus conhecimentos. $\mathrm{O}$ trabalho de grupo permite que os interactantes façam 
experiências, reelaborem suas falas, realizem autocorreções e heterocorreções e colaborem na construção do discurso para que a tarefa seja levada a termo (GRIGGS, 1998). Em síntese, a interação entre pares promove a produção e a negociação, atitudes consideradas condições necessárias para a aquisição/aprendizagem da LE, sendo que a produção permite que o aprendiz note e teste suas hipóteses (SWAIN, 1985) e a negociação torna o input compreensível (ver, dentre outros, LONG, 1996).

Em uma situação colaborativa de aprendizagem entre pares, haverá um uso linguístico funcional e expressivo, voltado para o interlocutor e próximo das necessidades reais de aprendizagem. De acordo com a competência que os aprendizes possuem na língua alvo e com os papéis que os interactantes tendem a assumir no decorrer da interação, haverá um conjunto de estratégias como negociações, reformulações, auto e heterorreformulação extremamente úteis para fins de aquisição/aprendizagem da LE, dado que aparecem em sequências em que os aprendizes negociam entre si o sentido para produzir um output mais correto (LONG, 1996).

Os estudantes serão livres de dispor de todo o tempo necessário para a elaboração de suas próprias estratégias de aprendizagem e contarão com os processos do grupo seja para estabelecer formas colaborativas seja para dirigir sua aprendizagem (CILIBERTI, 2012).

\section{OS MARCADORES DISCURSIVOS}

A análise dos assim chamados SD é uma das áreas de intersecção entre análise linguística e análise interacional ou, podemos dizer também, entre gramática e pragmática.

Uma primeira observação sobre os estudos dedicados aos SD diz respeito à variedade da terminologia adotada, visto que são chamados partículas pragmáticas, sinais discursivos, partículas conversacionais, conectores textuais ou discursivos ${ }^{4}$. Em italiano foram empregados os termos focalizadores (ANDORNO, 2000), marcadores pragmáticos (STAME, 1999), sinais discursivos (BAZZANELLA, 2006, 1994), conectores textuais (BERRETTA, 1984). Neste trabalho, adotaremos exclusivamente o termo SD devido à sua maior difusão.

Um ponto de desacordo entre os pesquisadores diz respeito às categorias gramaticais que podem ser incluídas em uma descrição dos SD. Embora a maior

4 A complexa temática terminológica não será abordada nesse trabalho; sobre isso, ver Stame (1999). 
parte dos estudiosos admita que eles pertencem a diferentes categorias gramaticais, cada autor acaba propondo distinções específicas. Por exemplo, alguns distinguem os marcadores das interjeições (FRASER, 1990), mas, em outras abordagens, elementos tradicionalmente considerados como simples respostas conversacionais são incluídos entre os marcadores (MASCHLER, 1997).

A literatura sobre os SD, de uma ótica pragmática, é ampla e variada para os objetivos que nos interessam. Concordamos com os estudiosos da conversação que consideram SD os elementos que podem ser atribuídos a categorias gramaticais heterogêneas, que "esvaziando-se em parte de seu sentido originário, adquirem valores acrescidos e servem para destacar a estruturação do discurso, colegar elementos frasais, interfrasais, extrafrasais e explicitar a colocação do enunciado em uma dimensão interpessoal, salientando a estrutura interativa da conversação" (BAZZANELLA, 2006, p.455, tradução nossa). O que caracteriza o emprego dessas formas é a relevância do contexto, linguístico e extralinguístico, que influencia seu uso e sua interpretação, porque "seu sentido primário não varia fundamentalmente, mas adquire nuances que dependem do contexto linguístico" (BAZZANELLA, 1995 , p. 225, tradução nossa) e, por isso, são chamados "polifuncionais" (BAZZANELLA, 2006, tradução nossa). Por esse motivo é extremamente difícil e delicada sua classificação. Em linhas gerais, concordamos com Schiffrin (1992) quando destaca que é justamente o caráter de "abertura potencial" (p. 363, tradução nossa) dos SD que torna difícil sua categorização.

Outra consequência importante de uma definição flexível dos SD é a constatação de uma possível especialização em suas funções. Com efeito, muitos estudos demonstraram que os SD podem ter funções específicas em contextos como as aulas escolares (BAZZANELLA, 1994; PUGLIESE, 2015) e os encontros terapêuticos (CONTENTO, 1994).

Embora sejam manifestações linguísticas pouco importantes para a realização do conteúdo proposicional dos enunciados (BLAKEMORE, 1987), porque se trata, geralmente, de conjunções, advérbios, interjeições e também de expressões frasais desemantizadas de seu conteúdo original, do ponto de vista discursivo os SD desempenham um papel fundamental porque têm a tarefa de reforçar a organização argumentativa do discurso. Por isso podem representar, como evidenciam alguns estudos (BIRELLO, 2005; SAINZ, 2009; FERRONI, 2013), um obstáculo para quem está aprendendo uma LE, mesmo em contextos em que a LM é afim à LE.

\footnotetext{
5 A polifuncionalidade dos marcadores é apontada também por Beretta (1984), que trata dos tipos de relação semântico-discursiva dos conectivos e das formas, que vão desde as conjunções até frases inteiras.
} 
Tratando-se, como já salientamos, de uma pesquisa desenvolvida entre aprendizes ocupados na realização de um conjunto de atividades comunicativas, em dupla, neste trabalho abordaremos os SD com funções interacionais e metatextuais ${ }^{6}$. Cientes da polifuncionalidade e das dificuldades taxionômicas referentes aos SD, por clareza expositiva tomaremos como base a classificação elaborada por Bazzanella $(2006,1994)$ que, levando em conta que a conversação é fruto de uma colaboração em que as contribuições do falante do turno e do interlocutor se entrelaçam até quase se confundir, propõe uma classificação dos SD bipartida: aqueles pronunciados pelo falante, ou seja, aquele que pronuncia um determinado enunciado naquele dado momento, e aqueles pronunciados pelo interlocutor, ou seja, aquele que participa da troca comunicativa sem que seja seu turno naquele momento (e, portanto, participa em silêncio ou por meio de sinais não verbais ou SD específicos). Ver a tabela n.1 extraída de Bazzanella (1994, p. 151).

\section{Tabela 1"Simetricidade" dos marcadores discursivos}

\begin{tabular}{|c|c|}
\hline FALANTE & INTERLOCUTOR \\
\hline $\begin{array}{l}\text { 1.a mecanismos de tomada de turno (ex. allora, } \\
\text { ecco, ma) }\end{array}$ & $\begin{array}{l}\text { 1. mecanismos de interrupção (ex. ma, allora, } \\
\text { insomma) }\end{array}$ \\
\hline \multicolumn{2}{|l|}{$\begin{array}{l}\text { 1.b mecanismos para manter o turno e preencher } \\
\text { lacunas (ex. mah, allora, cioè, sicuramente) }\end{array}$} \\
\hline \multicolumn{2}{|l|}{ 1.c mecanismos para ceder o turno (ex. no) } \\
\hline $\begin{array}{l}\text { 2. pedido de atenção (ex. senta/i, guardi/a; dica/ } \\
\text { dimmi) }\end{array}$ & 2. confirmação de atenção (ex. davvero, mh) \\
\hline $\begin{array}{l}\text { 3.a assunzione de consenso (ex. no, vero, non è } \\
\text { così, eh!) }\end{array}$ & 3. confirmação de consenso \\
\hline \multirow[t]{2}{*}{$\begin{array}{l}\text { 3.b pedido de consenso e/ou confirmação (ex. eh! } \\
\text { no) }\end{array}$} & $\begin{array}{l}\text { 3.b reforço (ex. esatto, perfetto, assolutamente, } \\
\text { come no) }\end{array}$ \\
\hline & 3.c consenso parcial (ex. mhh) \\
\hline \multirow[t]{2}{*}{ 4. controle da recepção (ex. eh, capisci, capito) } & $\begin{array}{l}\text { 4.a confirmação da recepção (ex. sì, ho capito, ah, } \\
\text { aah, oh) }\end{array}$ \\
\hline & 4.b pedido de explicação (ex. eh! aah, oh) \\
\hline $\begin{array}{l}\text { 5. fatismos, mecanismos de modulação (ex. ehi } \\
\text { capo) }\end{array}$ & 5. fatismos (ex. so bene, lo credo, povero/a) \\
\hline
\end{tabular}

6 Os marcadores metatextuais, como, por exemplo, "proprio, appunto, ecco, diciamo, insomma", referem-se à articulação das várias partes do texto; os marcadores pragmáticos/fáticos, como, por exemplo, "vero, capito, davvero, scusa", estão ligados à atitude do falante em relação à interação em curso (BAZZANELLA, 2006). 


\section{O CONTEXTO}

Qualquer pesquisa sobre aprendizagem das línguas - e muito mais sobre interação - deveria, como observa Cambra (2003), partir de uma descrição detalhada do contexto social e cultural ${ }_{i}$ por isso, nessa parte buscaremos apresentar um quadro exaustivo do contexto em que foi adquirindo forma o presente estudo.

Vamos comparar aqui os dados provenientes de dois contextos universitários de italiano LE na presença de LM afins (CS em um caso, PB no outro). A Espanha e o Brasil apresentam contextos bastante diferentes em relação à Itália. Na Espanha, e mais concretamente em Barcelona, a presença do italiano no contexto institucional é bastante forte em Universidades, IIC, escola superiores e Escuelas Oficiales de Idiomas (BIRELLO; FANTUZZI, 2003), e é fortalecida graças às trocas culturais constantes e à grande mobilidade que existe entre esses dois países. No Brasil e, mais precisamente, em São Paulo, que apresenta o polo urbano italiano maior do mundo, com cerca 15 milhões de habitantes de origem italiana (FONDAZIONE MIGRANTES, 2006), a língua italiana é uma lembrança distante, dado que se trata, na maioria dos casos, de descendentes de imigrados de segunda, terceira e quarta geração que não falam mais italiano (FERRONI, VELOSO; MORDENTE, 2014). A isso precisa acrescentar que, por motivos geográficos evidentes, os contatos com a Itália não são muito intensos. Entretanto, a promoção da cultura e da língua italiana em São Paulo é garantida, entre outras, pela escola Eugenio Montale, o Instituto Italiano de Cultura e o curso de graduação em Língua e Literatura da Universidade de São Paulo, instituições que, além de difundir a língua, dedicam-se à formação dos futuros docentes e expertos do setor.

Os dados que vamos examinar ao longo desse estudo foram levantados em um contexto universitário. Na Espanha foram extraídos dos cursos de italiano LE no Centro Linguístico da Universidade de Barcelona. Os dois grupos (ao todo cerca de trinta estudantes), de um nível que se situa entre A2 e B1 do Quadro Europeu Comum de Referência (doravante QECR, 2002), eram compostos, em maioria, por estudantes regularmente inscritos em um curso de graduação, mas também por estudantes não universitários. De qualquer forma, tratava-se de estudantes bilíngues CS. Os cursos eram ministrados, em um caso, por um professor catalão com formação na Itália, no outro, por um professor italiano.

Em São Paulo, a classe era formada por seis estudantes de LM português variante-brasileira, inscritos em um curso de Língua e Literatura Italiana de nível 
A2/B1 do QECR (2002). O curso era ministrado por um professor cuja LM é o italiano, com formação na Itália.

Dado que o contexto é definido também com base nas atividades que os participantes estão realizando (GAJO; $\left.\mathrm{KOCH}_{i} \mathrm{MONDADA}, 1996\right)$, é bom esclarecer que a metodologia usada seja na Espanha seja no Brasil baseavase em tarefas "[...] um trabalho de sala de aula que envolve os aprendizes na compreensão, manipulação, produção ou interação na língua-alvo, enquanto sua atenção está focada principalmente no sentido, em lugar da forma" (NUNAN, 2004, p. 10, tradução nossa). A tipologia das atividades era bastante variada, mas nesse estudo foram examinadas somente as "tarefas criativas" (WILLIS, 1996, tradução nossa) atividades realizadas em grupos pequenos, destinadas a promover a interação e que incluíam tipologias diferentes de tarefas.

\section{METODOLOGIA}

A presente pesquisa valeu-se dos instrumentos disponibilizados pela abordagem etnográfica (VAN LIER, 1988; WATSON-GEGEO, 1997). O corpus PB é formado por 15 horas de gravação áudio; o corpus CS por 30 horas de gravação áudio e vídeo.

Durante as gravações, ou logo depois, foram feitas anotações sintéticas sobre o esquema do setting com a disposição dos lugares e os nomes dos alunos e dos professores, bem como sobre o assunto da aula. A modalidade de observação que adotamos situa-se a meio caminho entre os dois polos que Duranti (1997, p. 99, tradução nossa) define como "participação passiva" e "participação completa". Com efeito, interviemos somente quando os participantes nos convidaram a tomar parte dos eventos comunicativos. Durante a fase de transcrição, às vezes tivemos dificuldade de entender as falas dos estudantes no decorrer das interações, porque as falas podem ser incompreensíveis por causa de barulhos, da sobreposição de vozes e do tom de voz muito baixo. Por esse motivo, as sequências examinadas podem resultar fragmentárias e pouco claras ${ }^{7}$.

Após termos concluído as gravações das aulas e a respectiva transcrição, dedicamo-nos a identificar os episódios comunicativos de que se compunha cada aula e que chamamos "segmentos" (CAMBRA, 2003, p.104, tradução nossa). Os

7 Os exemplos citados foram transcritos fielmente e podem conter imprecisões em relação à língua alvo. 
critérios que identificam as fronteiras dos segmentos e que guiam a análise dos dois corpora são: o tópico, a atividade de aprendizagem e o formato de participação interativa (CAMBRA, 2003, p. 104) ${ }^{8}$.

Essa macrounidade de análise nos permitiu obter uma visão rápida do modo como cada aula se desenrolava: as atividades realizadas, os conteúdos que foram trabalhados em termos de competência de linguagem e/ou de aprendizagem e as estruturas de participação em que se organizou o grupo/turma para a construção da comunicação verbal. Além disso, possibilitou ver, de forma clara e concreta, os SD utilizados pelo falante e polo interlocutor (BAZZANELLA, 2006, 1995).

Com relação aos $\mathrm{SD}$, efetuamos sua contagem em cada segmento e constatamos que eles aumentavam de maneira relevante, seja no corpus PB seja no corpus CS, no decorrer do trabalho entre pares.

Para cada uma da seis aulas do corpus PB, identificamos cerca de 24 SD, sendo que mais da metade ocorreu durante o trabalho de grupo, produzidos seja pelo falante seja pelo interlocutor. São eles. Os sinais referentes à concordância (14 ocorrências), sinais referentes à recepção (7 ocorrências) e os fatismos (3 ocorrências).

No corpus CS identificamos, ao todo, 41 ocorrências. Nesse caso também os SD são empregados seja pelo falante seja pelo interlocutor. Trata-se, geralmente, de SD úteis para gerenciar a atividade ou reformular um enunciado ou introduzir um comentário (29 ocorrências), demonstrar concordância ou avaliar o que foi dito pelo colega (10 ocorrências) ou fazer uma autoavaliação do que foi dito pelo falante (2 ocorrências).

Para identificar e descrever os SD produzidos pelos estudantes no decorrer das tarefas, efetuamos microanálises de cada segmento. Visto que, no decorrer da microanálise, muitos SD tendiam a se repetir, a fim de evitar a redundância selecionamos para cada SD um único exemplo que apresentaremos na seção a seguir.

8 O tópico é aquilo de que se fala. Trata-se, em termos didáticos, do conteúdo da aula, daquilo que pode ser objeto de aprendizagem pelo aluno. As atividades de aprendizagem são definidas como todas aquelas que são realizadas no âmbito das tarefas de aprendizagem, atualizando de alguma forma as planificações dos professores e as propostas dos manuais, resultando assim da articulação entre as intenções dos agentes educativos e o seu comportamento real em situação. Quanto ao formato de participação interativa, Cambra (2003, p. 104) identifica várias estruturas de participação básicas: interação na qual quer o professor quer os alunos compartilhem o poder interativo; estrutura que ocorre quando o professor desempenha plenamente a sua função de vetor de informação; quando o professor, controlando a interação, questiona os alunos e esses respondem, tomando a palavra; o trabalho de grupo; o trabalho autônomo em que o aluno se confronta com os documentos. 


\section{ANÁLISE DOS DADOS: OS SD DO FALANTE}

\subsection{Os SD do corpus PB}

No corpus $\mathrm{PB}$, os $\mathrm{SD}$ do falante são mais salientes, pertencem à categoria das interjeições e dos advérbios e são quase sempre expressos em PB. Sendo polifuncionais, observamos que um mesmo marcador pode desempenhar funções diferentes, como é o caso do marcador "né", derivado da transformação da matriz "isso não é verdade", que, além de ser o mais frequente, aparece nos turnos do falante em posição final e com entoação ascendente, para pedir confirmação daquilo que foi dito, dado que o aprendiz não está convencido da verdade de seu enunciado. Aparece geralmente na presença de frases interrogativas utilizadas por aquele que detém o turno da palavra para expressar dúvidas sobre o funcionamento da língua, dúvidas que podem ser de natureza gramatical ou referentes ao desenvolvimento da tarefa atribuída. Trata-se de um sinal que se refere ao consenso. Em I é expresso no final do turno por meio de "no?, vero?, non è così?, eh!, dico male?, eh?", marcadores de pedido de concordância e/ou confirmação (BAZZANELLA, 2006), e de alguma forma pode indicar que o falante poderia estar disposto a ceder seu turno. Em PB, por meio das variáveis "né, não é?, sabe, certo?" (URBANO, 1997, p. 97) ${ }^{9}$. No exemplo 1, Ângela e Paulo estão procurando responder a uma pergunta sobre a função do tempo verbal imperfeito. Ângela usa o marcador "né", no final do turno (linha 1), para obter o consenso ou pedir confirmação ao colega que considera mais experiente do que ela, já que tudo indica que é esse o papel que ela decide atribuir a ele; Paulo intervém prontamente para manifestar sua concordância por meio do SD "si”" (linha 2).

Exemplo $1^{10}$

1 Ângela: come ha detto? imperfetto::: immobilità né $=$ Ângela: como disse? Imperfeito::: imobilidade né=

9 Os SD na língua PB foram classificados por Marcuschi (1986) e Urbano, (2006, 1997), a partir de um corpus de conversações levantadas entre falantes cultos.

10 Normas para a transcrição:..., ..., etc.: pausa breve;

$=$ : dois turnos de palavras em sobreposição;

((inc)), ((risos)): o parêntese duplo indica uma parte da conversação incompreensível ou comentários sobre a transcrição, como risos etc.;

-: indica uma interrupção brusca;

:::: os dois pontos repetidos por três vezes de seguida indicam um som prolongado;

?: entoação ascendente;

!: entoação descendente,

testo: fenômeno que se deseja destacar. 
2 Paulo: = sì...

Paulo: $=$ sim...

3 Ângela: ci sono altri esempi?

Ângela: existem outros exemplos?

4 Paulo: mi pare di no

Paulo: me parece que não

Tudo isso fica ainda mais claro se tomarmos o exemplo 2 no qual uma dupla de estudantes está formulando hipóteses sobre algumas fotografias. Visto que não tem certeza que o termo "uniforme" esteja correto ${ }^{11}$, Francisca busca a aprovação do colega, inserindo no final do turno o SD "né" (linha 7).

\section{Exemplo 2}

5 Francisca: qui sono ragazzi di::: come si dice? con i vestiti di:::

Francisca: aqui estão garotos de::: como se diz? com roupas de:::

6 Luís: scuola non lo so

Luís: escola não sei

7 Francisca: questa cosa uniforme né ((em voz muito baixa e rindo))

Francisca: esta coisa uniforme né

8 Luís: uniforme ... è non lo so io non credo un viaggio

Luís: uniforme.... é não sei eu não acredito uma viagem

9 Francisca: è un viaggio la vita sono gli avvenimenti della sua vita fin dal ((inc)) scuola c'è questo titolo né

Francisca: é uma viagem a vida são os acontecimentos da sua vida desde a ((inc)) escola tem este título né

10 Luís: ((lendo)) il diario delle cacridobo

Luís: o diário de cacridobo

Os SD "tá"12 e "né" podem ocupar a posição final do enunciado daquele que detém o turno para tornar a conversação mais fluente. Eles funcionam como fatismos e são utilizados para "salientar o aspecto fático, ou seja, de 'coesão social' da comunicação, entendida como instrumento para criar, consolidar ou evidenciar o pertencimento de um indivíduo a um grupo" (BAZZANELLA, 2006, p. 456, tradução nossa). Consideramos significativo o exemplo 3 em que se tinha pedido

11 O termo correto em italiano seria "divisa".

12 Marcador que decore do seguinte processo de transformação: Está claro isso > Está claro > Claro?/ Tá". É usado em função de fático de natureza interrogativa no final de um enunciado (URBANO, 2006, p. 514). 
aos estudantes que formulassem hipóteses sobre o conteúdo de um trecho com base nas imagens. Essa sequência mostra claramente que os dois estudantes estão empenhados na atividade que lhes foi atribuída; ambos desejam terminar a tarefa mediante uma modalidade colaborativa e a presença do marcador "tá" (linha 11) indica precisamente o esforço realizado em conjunto.

\section{Exemplo 3}

11 Paulo: forse lui scrive::: sulla vita col suo fratello o con il suo giovane papà questi viaggi::: e::: il tempo è un tempo precedente non so degli anni::: cinquanta sessanta tá?

Paulo: talvez ele escreve::: sobre a vida com seu irmão e com o seu jovem pai estas viagens:: e::: o tempo é um tempo que precede não sei os anos:: cinquenta sessenta tá?

12 Catarina: perché?

Catarina: por quê?

13 Paulo: perché ci sono queste immagini di perché questi vestiti eh:::: antichi Paulo: porque existem estas imagens do porquê estas roupas eh:: antigas

14 Catarina: si può essere

Catarina: sim pode ser

A mesma coisa acontece no fragmento seguinte (linha 19), em que as estudantes devem reconstruir a parte de um trecho que foi omitida. Antes de chegar a um consenso, promovem uma discussão animada em que os turnos, embora se trate de uma conversação produzida em um contexto exolíngue, se sucedem de maneira natural e colaborativa:

\section{Exemplo 4}

15 Ângela: è perche dopo::: michelina:::

Ângela: é porque depois::: michelina:::

16 Francisca: ((indicando uma parte do texto)) ah è perché ob ((lendo)) minacciando di denunciarla al capo vagone quindi c'è qualcosa che::: lei ha fatto $=$ Francisca: ah é porque oh ameaçando denunciá-la ao treinador então é algo que::: ela fez $=$

17 Ângela: = ahn ahn

Ângela: $=$ ahn ahn

18 Francisca: hanno scoperto hanno detto a lei ah fai questa cosa un'altra volta::: oppure quando quando ((inc)) la minaccia fa qualcosa su quello che lei aveva già fatto per esempio fumare la sigaretta 
Francisca: descobriram disseram a ela ah faça esta coisa uma outra vez::: ou quando quando ((inc)) a ameaça faz algo sobre aquilo que ela já tinha feito por exemplo fumar um cigarro

19 Ângela: hai fumato::: una suora non può fumare non può avere i capelli rossi né! Ângela: fumou::: uma freira não pode fumar não pode ter os cabelos vermelhos né!

Pertencem à categoria dos fatismos também os $\mathrm{SD}$ usados pelo falante para chamar a atenção do colega. Se em I são realizados por meio dos verbos "guarda, vedi, senti" (BAZZANELLA, 2006), no corpus PB são expressos com a interjeição "oh"13, marcador linguístico não lexicalizado, empregado em PB para chamar o interlocutor, como no exemplo seguinte:

\section{Exemplo 5}

20 Ângela: è perche dopo::: michelina:::

Ângela: é porque depois::: michelina:::

21 Francisca: ((indicando uma parte do texto)) ah è perché ob ((lendo)) minacciando di denunciarla al capo vagone quindi c'è qualcosa che::: lei ha fatto $=$ Francisca: ah é porque oh ameaçando denunciá-la ao treinador então é algo que ::: ela fez $=$

22 Ângela: $=$ eh

Ângela: $=$ é

Há sequências menos relevantes do ponto de vista quantitativo nas quais os aprendizes, para resolver suas dúvidas, empregam os SD em LE. O SD mais frequente é "no", o qual, como acontece entre falantes de LM, aparece sempre no final do turno com entoação ascendente. Paulo e Catarina estão desenvolvendo uma tarefa preparatória (pre-task) e, devido à natureza da atividade, devem formular hipóteses com base em imagens (exemplo 6):

\section{Exemplo 6}

23 Paulo: questa foto mi ricorda::: il teatro no?

Paulo: esta foto me lembra::: o teatro não?

24 Catarina: mb...non so perché i vestiti sono veramente di quel tempo prima della guerra no?

13 Em italiano, porém, "ooh" indica recepção acompanhada de admiração (BAZZANELLA, 1990, p. 244). 
Catarina: mh... não sei por que as roupas são realmente daquele tempo antes da guerra não?

25 Paulo: sì antichi e c'è questo::: come si chiama questo bonde non è bonde Paulo: sim antigas e tem este::: como se chama este bonde não é bonde

26 Catarina: tram

Catarina: bonde

27 Paulo: tram

Paulo: bonde

28 Catarina: è un tram

Catarina: é um bonde

29 Paulo: sì è un tram

Paulo: sim é um bonde

No final do turno, ambos utilizam o sinal discursivo "no" para dar um tom de dúvida às suas suposições (linhas 23 e 24) e o SD "non so", precedido por uma hesitação "mh" (linha 24) e usado como um recurso para manter o turno de palavra e ganhar tempo.

O SD "vero", cujo equivalente em PB é "certo" (URBANO, 1997), tem uma função análoga àquela do sinal "no", mas é menos usado. Encontra-se no final do enunciado e é pronunciado com entoação ascendente. Veja-se o exemplo 7, no qual Luís e Ana devem corrigir uma redação escrita por outros colegas.

\section{Exemplo 7}

30 Luís: eh::: secondo me nella terza riga ((lendo)) pubblico che si interessa a si interessa a... vero? che si interessa!

Luís: é::: na minha opinião na terceira linha público que se interessa por se interessa por... não é? que se interessa!

31 Ana: di qualcosa

Ana: por algo

32 Luís: in portoghese em... no è che sembra molto strano che si interessa di turismo non lo so adesso che rileggiamo

Luís: em português em... não é que parece muito estranho que se interessa por turismo não sei agora que relemos

Quando os SD são expressos por meio da LM, os aprendizes tendem a diminuir as atividades de correção, (exemplo 8). 


\section{Exemplo 8}

33 Francisca: qui sono ragazzi di::: come si dice? con i vestiti di:::

Francisca: aqui tem garotos de::: como se diz? com roupas de:::

34 Luís: scuola non lo so

Luís: escola não sei

35 Francisca: questa cosa uniforme né ((em voz muito baixa e rindo))

Francisca: esta coisa uniforme né

36 Luís: uniforme ... è non lo so io non credo un viaggio

Luís: uniforme... é não sei eu não acredito uma viagem

37 Francisca: è un viaggio la vita sono gli avvenimenti della sua vita fin dal scuola c'è questo titolo né

Francisca: é uma viagem a vida são os acontecimento da sua vida desde a (( inc

)) escola tem este título né

38 Luís: ((lendo)) il diario delle cacridobo

Luís: o diário de cacridobo

Nesse fragmento, Francisca, devido também à presença do gravador que, em certo sentido, substitui a presença do professor (NUSSBAUM, 1990), empenha-se para que sua contribuição seja correta, como mostram as hesitações e as reformulações da linha 33. Dado que não conhece o termo italiano "divisa", busca a cumplicidade do colega por meio de um pedido de ajuda (linha 33), repetida na linha 35 . Luís, porém, talvez por ser menos competente ou por desejar concluir a tarefa atribuída, se abstém de iniciar atividades de heterocorreção/ heterorreparo e prefere terminar a atividade em lugar de corrigir as formas erradas, um procedimento geralmente empregado nas interações entre professor e aprendizes e que pode levar o aluno a adotar uma estratégia de evitamento (GRIGGS, 1998).

A ausência de uma atividade de negociação diante dos SD expressos em PB deve ser interpretada não tanto como um sinal de incapacidade linguística em LE, mas como desejo dos interactantes de levarem a termo a tarefa que lhes foi atribuída, dado que "a inserção de sequências pedagógicas na sequência principal serve para dirigir bruscamente o fluxo interacional [...], suspendendo e colocando em uma fase de estado de alerta forçado o termo do discurso e a atividade linguística que, até aquele momento, os interactantes estavam levando adiante" (ORLETTI, 2000, p. 122, tradução nossa). 


\subsection{Os SD do corpus espanhol}

No corpus CS, levantado na Espanha, os SD utilizados pelos estudantes em situações interativas, em duplas ou em grupos, são expressos, na maioria dos casos, em espanhol ou em catalão ${ }^{14}$ e, assim como acontece no corpus $\mathrm{PB}$, são expressos pelo falante mais do que pelo receptor. O SD mais saliente é "bueno", empregado especialmente como elemento conclusivo (exemplo 9) e, às vezes, para começar o turno de palavra (exemplo 10). No exemplo 9, Helena e Milena estão realizando uma atividade em que, após ter observado uma imagem, devem completar as frases de um exercício para reconstruir uma história representada em quadrinhos (negociação nos turnos 43-46). Na linha 47, após o SD "no"15 pronunciado com tom interrogativo para pedir confirmação, Helena encerra a conversação utilizando o SD "bueno". A troca interativa entre Helena e Milena é encerrada definitivamente pela intervenção do professor (linha 48), o qual, embora aprove com um "si" a escolha de "appartamento" (linhas 44 e 45) em lugar de "albergo" (linha 43), abstém-se de corrigir o SD utilizado em LM por Helena (linha 47).

\section{Exemplo 9}

43 Helena: albergo? no sé això és igual en un hotel cutre

Helena: hotel? não sei acho é igua em um hotel decadente

44 Milena: ah no no! un appartamento un appartamento

Milena: ah não não! um apartamento um apartamento

45 Helena: un appartamento

Helena: um apartamento

46 Milena: ((inc))

47 Helena: no? Bueno

Helena: não? Bom

48 Professor: sì

Professor: sim

No exemplo 10, ao contrário, o SD "bueno" é utilizado no começo do turno de palavra como sinal metadiscursivo (BRIZ, 1998; PORTOLÉS, 1998) ${ }^{16}$ para

14 Para esse estudo, embora existam no corpus espanhol também SD em catalão, analisamos somente aqueles em espanhol por serem os mais frequentes.

15 Diferentemente do que acontece no corpus PB, no corpus CS o SD "no" coincide nas três línguas envolvidas na aula: italiano, espanhol e catalão. Considerando a dificuldade de se distinguir o SD "no" nas três línguas, decidimos considerá-lo expresso sempre em língua italiana, uma vez que o grupo apresenta a tendência geral de utilizar o mais possível a língua alvo.

16 Briz (1998), Portolés (1998) e Briz, Pons e Portolés (2008) classificaram os SD no CS. 
ganhar tempo e organizar de maneira sequencial a resposta à pergunta iniciada no movimento anterior pelo professor (linha 49).

\section{Exemplo 10}

49 Professor: ((inc))

50 Janine: bueno stiamo praticando stiamo facendo la cosa vuol dire ridotto?

Janine: bom estamos praticando estamos fazendo a coisa quer dizer reduzida?

51 Professor: ridotto?

Professor: reduzido

Além de ser utilizado no começo e no fim de um turno de palavra, o SD "bueno" pode ocupar a parte central do próprio turno no intuito de retomar a atividade suspensa momentaneamente ou para fazer um comentário e ampliar a informação dada (exemplo 11). Em alguns casos é empregado também para retificar ou substituir o que foi dito antes, função descrita por Briz, Pons e Portolés (2008), que, por sua vez, coincide com o começo de um assunto novo (exemplo 12).

No exemplo 11, Maria e Marina estão respondendo a um conjunto de perguntas propostas pelo professor, com o objetivo linguístico de induzir o uso do passato prossimo. As duas estudantes transformam o exercício em uma verdadeira conversação em que há um interesse sincero por aquilo que a colega diz e, de fato, fornecem muitas informações que não são exigidas pela atividade. O SD "bueno" que aparece na linha 69 tem justamente a função de encerrar essa troca de informações iniciada pela pergunta "lo sai parlare bene tu il francese?" (linha 53) e de introduzir a pergunta sucessiva "bevi alcolici?" (linha 69).

\section{Exemplo 11}

53 Maria: lo sai parlare bene tu il francese?

Maria: você sabe falar bem o francês?

54 Marina: sì io sì!

Marina: sim eu sim!

55 Maria: da quanto tempo?

Maria: faz quanto tempo?

56 Marina: io l'ho imparato ho cominciato a impararlo m::: quando aveva diciotto anni ma l'ho imparato molto rapido

Marina: eu o aprendi comecei a aprendê-lo m::: quando tinha dezoito anos mas o aprendi muito rápido

57 Maria: sì? 
Maria: sim?

58 Marina: sì perché sono andata in Francia ho avuto ragazzi francesi ((risos)) e questo:: ((inc)) ho vissuto anche con estranieri e poi e:::m di solito io lavoro con francesi allora mi piace! il francese mi piace moltissimo

Marina: sim porque fui à França tive namorados franceses e isto::: eu também vivi com estrangeiros e depois e:: $\mathrm{m}$ geralmente eu trabalho com franceses então eu gosto dos franceses eu gosto muitíssimo

59 Maria: es que a me a me non piace

Maria: é que eu eu não gosto

60 Marina: mio marito,..., lui non piaceva niente i francesi io le dicevo vai a francese! io lavoro per ((inc)) per loro e loro mi danno soldi mi danno i soldi per vivere e lui rideva e allora adesso è da un anno e mezzo lui lavora per una ditta francese= Marina: meu marido... ele não gosta nada os franceses eu dizia a ele vai à francês! eu trabalho para para eles e eles me dão dinheiro me dão os dinheiros para viver e ele ria e então agora é faz um ano e meio ele trabalha para uma firma francesa= 61 Maria: sì?

Maria: sim?

62 Marina: $=$ e allora $=$ Marina: $=$ e então $=$

63 Maria: gli hanno chiesto di fare:::

Maria: pediram pra ele para fazer:::

64 Marina: =allora ha corsi di francese ((inc)) e adesso lui e::: piace molto il francese anche mi chiede di andare in Francia

Marina: = então tem cursos de francês e agora ele e::: gosta muito o francês também me pede para ir à França

65 Maria: io odiavo i francesi ma::: l'estate scorsi io::: scendere

Maria: eu odiava os franceses mas::: no verão passado eu::: descer

66 Marina: salire

Marina: subir

67 Maria: no salire è ((da sotto))

Maria: não subir é

68 Marina: ma scendere è ((inc))

Marina: mas descer é

69 Maria: ((inc)) arrivare più alto ho bisogno di parlare francese bueno bevi alcolici? Maria: chegar mais alto preciso falar francês bom bebe bebida alcoólica? 
No exemplo 12, Sílvia utiliza o SD "bueno" para retificar o que tinha dito antes no mesmo turno (linha 70). Nesses dois últimos casos, o SD está dentro do turno: em um caso (exemplo 12), ele assinala término da troca e a abertura de outra; no outro caso (exemplo 13), serve para fazer um esclarecimento sobre o que foi expresso pela própria falante.

\section{Exemplo 12}

70 Sílvia: vorrei andare bueno vorrei fare un viaggio ma forse non posso perché non ho soldi e::: e devo::: devo rimanere::: qui per casarmi

Sílvia: gostaria ir bom gostaria de fazer uma viagem mas talvez não posso porque não tenho dinheiro e::::e devo::: devo ficar::: aqui para me casar

Em algumas ocasiões, o SD "bueno" é acumulado (BAZZANELLA, 1994), ou seja, é usado em dupla com outros SD. No exemplo 13, Marcella declara sua total discordância com aquilo que foi dito por seu interlocutor, associando o SD "bueno" ao "pues" (linha 73). O duplo SD "bueno pues" parece reforçar a discordância existente entre as duas estudantes.

\section{Exemplo 13}

71 Marcela: ma mi sembra che non è lo stesso dall'americano all'inglese

Marcela: mas me parece que não é o mesmo do americano para o inglês

72 Lourdes: sì::: è lo stesso, io credo di sì! ((risos))

Lourdes: sim::: é o mesmo, eu acredito que sim!

73 Marcela: bueno pues io credo di no!

Marcela: bom pois eu acredito que não!

Outro sinal muito frequente no CS è "vale", SD usado seja pelo falante que pelo interlocutor.

No exemplo 14, observamos o uso repetido de "vale" (linha 84) para aceitar a reflexão metalinguística feita sobre a língua. Sobre a relação do som [J] com a grafia, "sc", na linha 77 Carolina manifesta uma dúvida que leva Tina a fazer uma reflexão. Em primeiro lugar, Tina indica que o som em questão se transcreve com um " $\mathrm{x}$ " (grafia do catalão que corresponde ao som [S]) e pronuncia em voz baixa a palavras para entender melhor (linha 82). Em seguida, passa para a regra de pronúncia do espanhol (linha 84) pronunciando [ $\theta$ ] a letra " $\mathrm{c}$ " seguida pela vogal " $\mathrm{i}$ " (talvez para tornar mais fácil a compreensão da colega). Finalmente, encerra o turno com uma avaliação de sua reflexão por meio do uso repetido do SD "vale". De acordo com 
Briz, Pons e Portolés (2008), por meio da repetição o falante expressa, de maneira forte, sua concordância com aquilo que foi dito por outros.

\section{Exemplo 14}

74 Mônica: salvietta che è?

Mônica: salvietta o que é?

75 Professor: asciugamani

Professor: toalhas

76 Tina: asciugamani ((inc)) aunque

Tina: toalhas embora

77 Carolina: asciugamani?

Carolina: toalhas?

78 Tina: asciugamani a y sciugamani

Tina: toalhas a e toalhas

79 Carolina: ((inc))

80 Tina: una equis y ahora no lo sé pero creo

Tina: um x e agora não sei porém creio

81 Carolina: ((inc))

82 Tina: asciuga ((em voz baixa, como se estivesse falando sozinha)) asciuga

Tina: seca seca

83 Carolina: a-sciu-ga

Carolina: se-ca

84 Tina: [as $\theta$ iuga as $\theta$ iuga] vale vale

Tina: [seca seca] ok ok

Em alguns casos, "vale" pode ser usado pelo falante e pelo interlocutor para demonstrar que concordam sobre algo e encerrar a troca interativa. No exemplo 15, Daniela e Janine estão realizando um exercício repetitivo que tem o objetivo de focalizar a atenção das aprendizes na forma. A estrutura interativa reproduz a clássica sequência IRA, com a diferença que quem a conduz não é o professor, mas uma estudante que emprega "vale" em terceira posição (linha 87) para aceitar/avaliar o que foi dito pela colega (linha 86) e encerrar a troca iniciada com o movimento 85 por meio de uma pergunta referente ao exercício.

\section{Exemplo 15}

85 Daniela: hai messi hai già messi tutti i piatti?

Daniela: você colocou já colocou todos os pratos? 
86 Janine: no! non li ho messi tutti Janine: não! não os coloquei todos

87 Daniela: vale!

Daniela: ok!

88 Janine: vale! ((risos)) hai messo la candela? Janine: ok! colocou a vela?

Nesse exemplo nota-se que seja o falante seja o interlocutor empregam o SD "vale" com o mesmo sentido. Daniela (linha 87) aceita como correta a proposta de Janine para terminar a atividade. De sua parte, Janine (linha 88) utiliza o SD "vale" para aceitar a confirmação de Daniela, para encerrar definitivamente a troca referente à pergunta iniciada na linha 85 e propor una nova pergunta "bai messo la candela" (linha 88).

Outro SD utilizado com certa frequência no corpus CS é "pues". Aparece na maioria dos casos em posição inicial e, em certas ocasiões, como se viu no exemplo 14, é usado em dupla com o SD "bueno". Quando sozinho, "pues" comporta-se como unidade fática, como elemento de continuidade com o que foi dito antes pelo interlocutor (CALVI, MAPELLI, 2004) ou para introduzir um comentário (exemplo 17). Janine, no exemplo 16 (linha 91), o emprega para expressar uma dúvida sobre aquilo que discutiu com a colega nos turnos precedentes.

\section{Exemplo 16}

89 Janine: se usiamo l'oggetto diretto dobbiamo fare la concordanza con il participio Janine: se usamos o objeto direto devemos fazer a concordância como particípio 90 Daniela: la chiave e ((inc)) plurale è le chiave,

Daniela: a chave e plural é as chave,

91 Janine: pues no sé Janine: pois não sei

O SD "pues" encontra-se no começo (mesmo que não necessariamente em primeira posição) do enunciado ou do fragmento do enunciado que contém a resposta. No exemplo 17, as alunas discutem (linhas 93 e 94) sobre o uso do verbo "cadere" que, em italiano, diferentemente do que acontece em espanhol, não apresenta a forma pronominal correspondente a "caerse". Janine (linha 95) usa o SD "pues" para: resumir o que foi discutido anteriormente, introduzir a reposta definitiva (e correta) para a frase apresentada no exercício e concluir a troca interativa. 


\section{Exemplo 17}

92 Daniela: ((inc)) come mai piange Roberto? è caduto per le scale. credo che sia caduto per le scale e sia fatto male

Daniela: como assim o Roberto está chorando? caiu pelas escadas. creio que tenha caído pelas escadas e tenha se machucado

93 Janine: si sia si sia caduto si sia o sia caduto?

Janine: tenha tenha caído tenha ou tenha caído?

94 Daniela: no no possa cadersi posa cadere

Daniela: não não pode cair pode cair

95 Janine: cadere pues sia caduto e si sia fatto male perché è si è no?

Janine: cair pois tenha caído e tenha se machucado porque é se é não?

Uma última observação deve ser feita a propósito das atividades de reparo que são totalmente ausentes tanto por parte dos colegas como por parte do professor quando os SD são expressos em LM. Veja-se o exemplo 9 (linha 48), no qual o professor, embora intervenha para confirmar a dúvida de natureza lexical manifestada pelas estudantes, deixa de sugerir a forma correspondente em italiano do SD espanhol "bueno", provavelmente porque a atenção, nesse momento, está toda focalizada na realização da atividade e não considera oportuno abrir uma sequência pedagógica (ORLETTI, 2000, p. 122) que poderia alterar a continuidade temática e provocar uma interrupção brusca do fluxo da conversação.

\subsection{OS SD DO INTERLOCUTOR}

\subsubsection{Os SD do corpus PB}

Os SD empregados pelo interlocutor pertencem geralmente à classe tradicional das "interjeições" e possuem um caráter avaliador, ou seja, expressam a opinião de quem formula e não exigem confirmação do destinatário. Isso comporta que, não podendo haver movimentos de reação por parte do autor do comportamento avaliado, as atividades de reparo são momentaneamente suspensas mesmo quando os SD são expressos em PB.

Pertencem a essa categoria os SD utilizados para expressar a concordância com o conteúdo proposicional do falante de turno. No corpus PB, os interlocutores manifestam sua participação seja por meio do SD italiano "si", seja por meio da forma não lexicalizada "ahn ahn", com pronúncia nasalizada típica do PB. Esses SD 
aparecem nos turnos dos interactantes em sobreposição com o turno do falante em curso. Veja-se o fragmento 18 em que se o "si" da linha 100 e aquele da linha 102 são empregados por Francisca para confirmar seu interesse; o terceiro "sì" que aparece no turno 104 é de outra natureza porque, além de indicar que o interlocutor acompanha com atenção o que está sendo dito pelo falante, expressa, por meio da interjeição "ah", um sentido de admiração, visto que a informação dada por Luís não é conhecida por Francisca.

\section{Exemplo 18}

96 Francisca: è vero ho detto un viaggio però non::: allora non mi pare che sia questo

Francisca: é verdade eu disse uma viagem porém não::: então não me parece que seja isso

97 Luís: no può essere un viaggio

Luís: não pode ser uma viagem

98 Francisca: può essere che ci sia un viaggio nella istoria ma non tutta la istoria sia un viaggio

Francisca: pode ser que não seja uma viagem na história mas não toda a história seja uma viagem

99 Luís: oh possiamo::: intendere come un sentido figurati- figurativo $=$

Luís: oh podemos::: entender como um sentido figurati- figurativo

100 Francisca: $=$ sì

Francisca: $=$ sim

101 Luís: la vita come un viaggio per esempio queste::: non so come dire queste caracteris $=$

Luís: a vida como uma viagem por exemplo estas:: não sei como dizer estas caracteris $=$

102 Francisca: $=$ sì

Francisca: $=\operatorname{sim}$

103 Luís: qua sono i caratteri della vespa la vespa si scrive con questa lettera qua Luís: aqui são as características da vespa a vespa se escreve com esta letra aqui

104 Francisca: ab sì!

Francisca: ah sim!

105 Luís: è sì l’antica

Luís: é sim a antiga

106 Francisca: no ma questa è una motoci- motocicletta bellissima

Francisca : não mas esta é uma motoci- motocicleta belissima 
No exemplo seguinte, ao contrário, Adriana manifesta sua participação empregando o marcador não lexicalizado "ahn ahn".

\section{Exemplo 19}

107 Ângela: è perche dopo::: michelina:::

Ângela: é porque depois:: michelina:::

108 Francisca: ((indicando uma parte do texto)) ah è perché ob ((lendo)) minacciando di denunciarla al capo vagone quindi c'è qualcosa che::: lei ha fatto $=$

Francisca:ah é porque oh ameaçando denunciá-la ao treinador então tem algo que::: ela fez $=$

109 Ângela: $=a b n a b n$

Ângela: $=$ ahn ahn

110 Francisca: hanno scoperto hanno detto a lei ah fai questa cosa un'altra volta::

Francisca: descobriram disseram para ela ah faça esta coisa uma outra vez::

Outra categoria é representada pelos SD referentes à recepção, por meio dos quais o interlocutor sinaliza que a recepção aconteceu, no sentido que compreendeu o que o falante disse no turno anterior. As formas mais frequentes comprovadas para o I são "sì, bo capito, ab, ok" (BAZZANELLA, 1995, p. 244) e para o PB "ahn ahn, certo, sim, claro, pois è, sei, ok" (URBANO, 1997, p. 2006). Para indicar que houve a recepção, os estudantes servem-se do indicador neutro "ok", comum a ambas as línguas e que aparece como reposta a sequências que contêm explicações de origem gramatical ou lexical, produzidas pelo estudante mais competente. Vejamos o fragmento 20, no qual Ana explica para a colega o que é "il quartiere Eur" e Mara confirma que a compreensão aconteceu por meio do SD "ok", precedido pela interjeição $=$ "ah", empregada nesse caso para expressar surpresa.

\section{Exemplo 20}

111 Ângela: quartiere che si chiama eur che mussolini ha creato proprio per fare un::: come si dice:::. fare la propaganda del fascismo $=$ Ângela: bairro que se chama eur que mussolini criou exatamente para fazer um::: como se diz::: fazer a propagando do fascismo $=$

112 Mara: $=a b_{::: o k}$

Mara: $=$ ah::: ok 


\subsubsection{Os SD do corpus CS: os SD do interlocutor}

Como já comentamos sobre o corpus $\mathrm{PB}$, também no corpus CS aparecem SD que pertencem à classe das "interjeições" e têm um viés avaliador graças ao qual o falante expressa sua opinião sem que seja necessária a confirmação por parte do destinatário. Diferentemente do que acontece no corpus PB, o SD "ok", embora seja muito utilizado pelo professor nativo, aparece no discurso dos estudantes apenas duas vezes, uma vez sozinho e outra vez acompanhado por "ah". Muito usado é o SD "sì" que, porém, por ser idêntico nas três línguas, torna difícil dizer se está sendo usado em italiano, espanhol ou catalão ${ }^{17}$.

"Vale" é um dos SD entre os mais salientes e serve ao interlocutor especialmente para indicar concordância com aquilo que foi expresso pelo falante, como se pode ver nas linhas 116 e 119 do exemplo 21. Nesse contexto de aprendizagem, um dos empregos mais frequentes de "vale" é certamente demonstrar concordância com o que foi dito pelo/pela colega e continuar a construir juntos o sentido daquilo que deseja dizer.

\section{Exemplo 21}

113 Ester: sedici! que he dicho yo! ((risos)) sedici sedici è un anello e secondo il colore è come si mostra mostra $=$

Ester: dezessei! dezessei! se você diz é um anel e de acordo com a cor é como se mostra mostra $=$

114 Ruth: il carattere

Ruth: o caráter

115 Ester: $=$ il carattere o l'estado de ánimo della persona che lo porta

Ester: = o caráter ou o estado de ânimo da pessoa que o usa

116 Ruth: vale si tu sei arrabbiata /è nero/

Ruth: ok se você está brava /fica preto/

117 Ester: /è nero/ si sei contenta è::: no sé blu si sei innamorata

Ester: /fica preto/ se está contente é::: não se é azul está apaixonada

118 Ruth: credo che direttamente sia una specie de anello ma un anello cibernetico Ruth: acredito que diretamente seja uma espécie de anel mas um anel cibernético

119 Ester: vale un anello cibernetico ((risos)) sì sono d'accordo. siete d'accordo?

Ester: ok um anel cibernético se concorda concordam?

17 Devido à dificuldade de distinguir o "sì" nas três línguas, decidimos considerar esse SD expresso sempre em língua italiana, com base na tendência geral do grupo de empregar, na maioria das vezes, a língua alvo. 
No exemplo 21, as estudantes estão formulando hipóteses sobre as fotografias que representam objetos que podem ser interpretados de diferentes maneiras. As estudantes utilizam o SD "vale" em duas ocasiões. No turno 116, Ruth aceita a proposta de Ester (linha 115), porém a amplia. Sucessivamente, na linha 118, faz outra proposta que é aceita por Ester com o SD "vale", seguido pela repetição do objeto e da pergunta dirigida aos demais colegas para ver se todos concordam (linha 119).

O SD "vale" é empregado também para demonstrar que se entendeu aquilo que foi dito antes e, com frequência, é precedido pelo SD "ah". Com a dupla "ah vale", segundo Briz et al. (2008), Madalena (linha 126, exemplo 22) expressa que entendeu um ponto complicado discutido nos turnos precedentes:

\section{Exemplo 22}

120 Catarina: sono andata a Roma ,..., quando avevo dieci anni ,..., come si dice sono andata a Roma a:::

Catarina: fui para Roma ,..., quando tinha dez anos ,..., como se diz fui para Roma a::

121 Professor: a dieci anni o quando avevo

Professor: há dez anos ou quando tinha

122 Catarina: a dieci anni

Catarina: há dez anos

123 Professor: a dieci anni

Professor: há dez anos

124 Madalena: o può essere dieci anni fa

Madalena: ou pode ser faz dez anos

125 Catarina: no! perché aveva dieci anni

Catarina: não! porque tinha dez anos

126 Madalena: ab vale!

Madalena: ah ok!

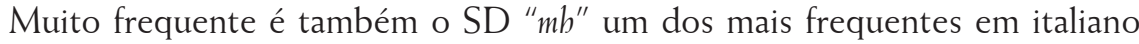
(BAZZANELLA, 1995) utilizado também em CS pata avaliar e confirmar, como no exemplo 23.

\section{Exemplo 23}

127 Janine: apparecchiare és parar la taula no?

Janine: arrumar é para a mesa não? 
128 Daniela: $\mathrm{mh}, \mathrm{mh}$

Daniela: $\mathrm{mh}, \mathrm{mh}$

Nesse caso também, como foi observado em relação a "si" e "no", devido à afinidade entre I e CS é difícil distinguir a língua em que foi utilizado o SD.

\section{CONSIDERAÇÕES FINAIS}

Da análise dos dois corpora surgiram características gerais sobre o uso dos SD entre aprendizes cuja LM é afim à LE, enquanto estão ocupados na realização de tarefas em duplas. Antes de tirar conclusões, é útil destacar que as atribuições de função não devem ser consideradas de maneira rígida, dado que o comportamento dos participantes é o resultado de uma escolha ativa em que a língua é, frequentemente, negociada entre dois ou mais falantes de maneira flexível, de acordo com as exigências de interação e do contexto. Convém salientar, também, outra característica dos $\mathrm{SD}$, que diz respeito ao uso individual: a preferência de uma pessoa pelo uso repetido de determinados SD (ou, muitas vezes, no interior de um contexto limitado).

Os SD usados pelos falantes em contextos interativos entre aprendizes de italiano LE cuja LM é o PB são:

- o SD "non so" usado em I para ganhar tempo e organizar a própria fala; esse SD não ocupa uma posição bem definida no interior do enunciado, mas é sempre precedido por pausas ou alongamentos vocálicos;

- os SD "tá, né" em PB e "no, vero" em I, que servem para buscar a aprovação do colega, dado que o falante tem dúvidas sobre o funcionamento da língua, dúvidas que podem ser de natureza gramatical, lexical ou referentes ao desenvolvimento da tarefa atribuída. Encontram-se sempre na parte final do enunciado e têm entoação ascendente;

- os SD "né, tá, oh" em PB e "no" em I, usados para salientar o envolvimento e o empenho para o desenvolvimento da tarefa; eles também aparecem no final do enunciado.

Os SD usados por falantes em contextos interativos entre aprendizes de italiano LE cuja LM é o CS são: 
- o SD "bueno" em CS, usado para encerrar o turno, para estruturar o discurso, para retificar ou para ampliar o que foi dito antes. O SD "pues" pode aparecer em posição final, no interior do enunciado e no final para introduzir um comentário, para resumir, para introduzir a resposta definitiva a uma frase do exercício, para concluir a troca interativa. Não é necessariamente a primeira palavra do enunciado, mas está sempre no começo da resposta propriamente dita;

- a combinação dos SD "bueno pues" em CS, cuja função é indicar uma discordância total com o interlocutor; o SD "vale, vale" em CS, que é repetido duas vezes para concordar com uma reflexão metalinguística.

Os SD usados por interactantes em contextos interativos entre aprendizes de italiano LE cuja LM é o PB são:

- os SD "si" em I e "ahn ahn" em PB usados para manifestar concordância sobre o conteúdo proposicional do falante de turno que se encontram em sobreposição com o turno do falante em curso;

- os SD neutros "ah, ok", usados pelo interlocutor para assinalar que a recepção aconteceu e que estão em sobreposição com o turno do falante em curso. Devido à afinidade entre as línguas envolvidas, não é possível estabelecer em que língua são pronunciados.

Os SD usados pelos interactantes em contextos interativos entre aprendizes de italiano LE cuja LM é o CS são:

- o SD "vale" em CS usado no começo do turno, sozinho ou associado ao SD "ah" para sublinhar a concordância e para indicar que se compreendeu um aspecto complicado discutido nos turnos precedentes;

- alguns SD "sì", "no", "mh", usados pelo interlocutor para assinalar que a recepção aconteceu. Devido à afinidade entre as línguas envolvidas, não é possível estabelecer em que língua são pronunciados.

Em geral, emergiu que aprendizes de italiano LE com LM afins têm um comportamento convergente em relação ao uso dos SD em contextos interativos. Com efeito, embora se trate de contextos de aprendizagem facilitados, dado que a língua de partida é afim à $\mathrm{LE}$, os $\mathrm{SD}$ são frequentemente expressos em ambos os corpora por meio do emprego da LM tanto por parte de quem detém o turno como por parte do interlocutor. A esse respeito os marcadores mais frequentes são né e tá 
em PB e vale e bueno in CS. Tratando-se de contextos colaborativos, a categoria dos SD mais representativa é aquela dos fatismos usados para manter viva a conversação e os mecanismos de aprovação usados para receber um feedback por parte do mais experiente linguisticamente. Os SD metatextuais estão completamente ausentes nos dois corpora, talvez porque seu uso exija uma competência linguística e conceitual que os aprendizes não possuem.

Os SD, mesmo quando expressados em $\mathrm{PB}$ e em CS, permitiram que os aprendizes mantivessem a estrutura conversacional aberta e facilitaram a intercompreensão. As atividades de reparo auto e heteroiniciadas pelos estudantes, usadas frequentemente para melhorar o seu próprio output e estimuladas também pela presença do gravador que, em certo sentido, substitui a presença do professor, tendem a desaparecer no momento em que os SD são expressos em PB e em CS, seja porque são muito fracos semanticamente, seja porque prevalece nos aprendizes o desejo de levar a termo a tarefa atribuída, dado que a inserção de sequências pedagógicas na sequência principal poderia mudar bruscamente a direção do fluxo interacional.

Consideramos que, com base na análise da interação que ocorre na aula de língua, podem-se extrair indicações didáticas claras e preciosas.

Em primeiro lugar, é possível afirmar que contextos como aqueles observados favoreceram a presença de determinados SD, característicos de situações menos formais e mais coloquiais. Esse dado levanta uma questão importante que deve ser examinada quando se leciona uma LE, ou seja, que se deve levar em conta, além das competências linguísticas que abrangem os setores da morfologia e da sintaxe, também a dimensão pragmática da língua com o objetivo de estimular nos aprendizes atenção e consciência em relação a alguns fenômenos pragmáticos, em lugar de fornecer somente regras prescritivas sobre o uso da LE. A percepção dos SD pode não ser tarefa fácil na aula de língua por causa de sua fragilidade fônica, polissemia e indefinição semântica, embora, come diz Schiffrin (1987), eles nunca sejam vazios e conservem uma ligação com seu "core meaning", que contribui para a realização de suas funções pragmáticas.

Isso aponta para a necessidade de elaboração de uma didática que apresente reflexões sobre e para o emprego dos SD desde os níveis iniciais, adequados para o nível de interlíngua e para suas necessidades comunicativas dos estudantes postos diante de uma determinada atividade. Dessa forma, também o professor terá a oportunidade de realizar reparos mais bem direcionados e de ajudar o aluno a incorporar o SD que é objeto de estudo. 


\section{REFERÊNCIAS BIBLIOGRÁFICAS}

ALBERT, J.L.; PY, B. (1986). Vers un modèle exolingue de la communication interculturelle: interparole, coopération et conversation. Études de Linguistique Appliquée. v.61, n¹, pp. 78-90.

ANDORNO, C. (2000). Focalizzatori tra connessione e messa a fuoco. Il punto di vista delle varietà di apprendimento. Milano: Franco Angeli.

BANGE, P. (1996). Considérations sur le rôle de l'interaction dans l'acquisition d'une langue étrangère. Les Carnets du Cediscor. v. 4, n 1, pp. 189-202.

BARNES, D; TODD, F. 1997). Communication and learning in small groups. London: Routledge \& Kegan Paul.

BAZZANELLA, C. (2006). Discourse Markers in Italian: towards a 'compositional' meaning. In: Fischer, K. (org.), Approaches to discourse particles. Amsterdam: Elsevier, pp. 449-464.

BAZZANELLA, C.. (1995). I segnali discorsivi. In: Renzi, L.; Salvi, G.; Cardinaletti, A. (orgs.), Grande grammatica italiana di consultazione, vol. III. Bologna: Il Mulino, pp. 226257.

BAZZANELLA, C.. (1994). I segnali discorsivi. In: Bazzanella, C. (org.), Le facce del parlare. Firenze: La Nuova Italia, pp. 145-174.

BERRETTA, M. (1984). Connettivi testuali in italiano e pianificazioni del discurso. In: Coveri, L. (org.), Linguistica testuale. Roma: Bulzoni, pp. 237-254.

BIRELLO, M. (2005). Las alternancia de lenguas en la clase de italiano lengua estranjera. Su uso en las interacciones en subgrupos de alumnos adultos en Cataluña. Tese de Doutorado em Didàctica de la Llengua i de la Literatura. Departament de Didàctica de la Llengua i la Literatura. Universitat de Barcelona, Barcelona.

BIRELLO, M.; FANTUZZI, S. (2003). "Spagna", In: Balboni, P.; Santipolo, M. (orgs.), L'italiano nel mondo. Mete e metodi dell'insegnamento dell'italiano nel mondo. Un'indagine qualitativa. Roma: Bonacci Editore, pp.168-172.

BLAKEMORE, D. (1987). Semantic contrastains on relevance. Oxford: Blackwell, 1987.

BRIZ, A. (1998). El español coloquial: Situación y uso. Madrid: ArcoLibros. .

BRIZ, A.; PONS, S.; PORTOLÉS, J. (2008). Diccionario de partículas discursivas del español. 2008. Disponível em: www.dpde.es. Acesso em: 7 agosto 2014.

BYGATE, M. (1998). Units of oral expression and language learning in small group interaction. Applied Linguistics. v. 9, $\mathrm{n}^{\circ} 1$, pp. 59-82.

CALVI, M.V.; MAPELLI, G. (2004). Los marcadores bueno, pues, en fin, en los diccionarios de español e italiano. Artifara, v. 1, n 4, 2004 disponível em: http://www.artifara.com/ rivista4/testi/marcadores.asp. Acesso em: 7 agosto 2014.

CAMBRA, M. (2003). Une approche ethnograpbique de la classe de langue. Paris: Didier.

CASTRO, R. V. (1989). A aula de português: um contexto especializado de comunicação. In: Sequeira, F. (org.), O ensino-aprendizagem do Português. Teorias e práticas. Braga: Universidade de Minho, pp. 13-29. 
CAZDEN, C. B. (1988). Classroom discourse: the language of teaching and learning. Portsmouth: Heinemann.

CILIBERTI, A. (2012). Glottodidattica: per una cultura dell' insegnamento linguistico. Roma: Carocci.

CONTENTO, S. (1994). I marcatori discorsivi del colloquio psicologico. In: Orletti, F. (org.), Fra conversazione e discorso. L'analisi dell'interazione verbale. Roma: La Nuova Italia Scientifica, pp. 217-232.

DURANTI, A. (1997). Linguistic antbropology. Cambridge: Cambridge University Press.

FASULO, A.; GIRARDET, H. (2002). Il dialogo nella situazione scolastica. In: Bazzanella, C. (Org.), Sul dialogo: contesti e forme di interazione verbale. Milano: Guerini Studio, pp. 59-72.

FELLIN, L.; PUGLIESE, R. (1994). I connettivi e i segnali discorsivi nell'apprendimento dell'italiano per scopi accademici in studenti di scambio internazionale. In: Atti del XXVI Congresso della Società di Linguistica Italiana, Siena 5-7 novembre 1992. Roma: Bulzoni, pp. 379389.

FERRONI, R.; VELOSO, F. S.; MORDENTE, O. A. (2014). Da una lingua all'altra: funzioni discorsive e identitarie della commutazione di codice in una famiglia di immigrati italiani residente a San Paolo del Brasile. Studi italiani di linguistica teorica e applicata. v. 43, $\mathrm{n}^{\mathrm{o}} 3$, pp. 465-486.

FERRONI, R.; (2013). As estratégias de comunicação durante a realização de tarefas feitas em colaboração por aprendizes de línguas próximas: rumo ao plurilinguismo. Tese de Doutorado em Língua, Literatura e Cultura Italianas. Departamento de Letras Modernas, Universidade de São Paulo, São Paulo.

FONDAZIONE MIGRANTES. (2006). Rapporto italiani nel mondo. Roma: Idos.

FRASER, B. (1990). An approach to discourse markers. Journal of Pragmatics, v. 14, n 1, pp. 383-395.

GAJO, L.; KOCH, P.; MONDADA, L. (1996). La pluralité des contextes et des langues: une approche interactionnelle de l'acquisition. Bulletin Suisse de Linguistique Appliqué, v. 64, nº 1, pp. 61-86.

GRIGGS, P. (1998). Cómo tratan los aprendientes adultos los problemas de lengua en tareas comunicativas efectuadas en pareja. In: Pujol Berché, Mi Nussbaum, L.; Llobera, M. (orgs.), Adquisición de lenguas extranjeras: perspectivas actuales en Europa. Madrid: Edelsa, pp. 207-218.

HALL, J. K. (1995). "Aw, man, where you goin?": classroom interaction and the development of L2 interactional competence. Issues in Applied Linguistics, v. 6, $\mathrm{n}^{\circ}$ 2, pp. 37-62.

LONG, M. H. (1996). The role of the linguistic environment in second language acquisition. In: Ritchie, W. C.; Bhatia, T. K. (orgs.), Handbook of second language acquisition. San Diego: Academic Press, pp. 413-468.

LÜDI, G.; PY, B. (1986). Être bilingue. Berna, Peter Lang. MARCUSCHI, L. A. (1986). Análise da conversação. São Paulo: Ática.

MASCHLER, Y. (1997). Discourse markers at frame shifts in Israeli Hebrew talk-ininteraction. Pragmatics, v. $7, \mathrm{n}^{\circ} 2$, pp. 183-211. 
MEHAN, H. (1979). Learning lesson: social organization in the classroom. London: Harvard University Press.

MORDENTE, O. A.; FERRONI, R.. (2015). Novas tendências no ensino/aprendizagem de línguas românicas e na formação de professores. Editora Humanitas: São Paulo.

NUNAN, D. (2004). Task-based Language Teacbing. Cambridge: Cambridge University Press.

NUSSBAUM, L. (1992). Manifestacions del contacte de llengües en la interlocució. Treballs de Sociolinguística Catalana. Barcelona, v. 10, n 1, pp. 99-125.

NUSSBAUM, L. (1990). Bueno, doncs, on commence?" Plurilinguisme a classe de llengua estrangera. Temps d'educació, Barcelona, v. 3, n 1, pp. 79-99.

ORLETTI, F. (1994). La conversazione diseguale. Potere e interazione. Roma: Carocci.

ORLETTI, F. (1994). Fra conversazione e discorso: l'analisi dell'interazione verbale. Roma: La Nuova Italia Scientifica.

PEKAREK, S. Formes d'interaction et complexité des tâches discursives: les activités conversationnelles en classe de L2. In: Cicourel, R.; Véronique, D. (orgs.). Discours, action et appropriation des langues. Paris: Publications de la Sorbonne Nouvelle, 2002, p. 117-130.

PORTOLÉS, J. (1998). Marcadores del discurso. Barcelona: Ariel.

PUGLIESE, R. (2015). Figurarti, tra i segnali discorsivi. Una prospettiva pedagogica. In: Pistolesi, E.; Pugliese, R.; Gili Fivela, B. (orgs.), Parole, gesti, interpretazioni. Roma: Aracne Editrice, pp. 163-207.

QUADRO comune europeo di riferimento per le lingue: apprendimento insegnamento valutazione. (2002). Firenze: La Nuova Italia-Oxford.

SAINZ, E. (2009). ¿Por qué resulta difícil comprender un marcador del discurso? In: Jamet, M.-C. (org.), Orale e intercomprensione tra lingue romanze: ricerche e implicazioni didattiche. Venezia: Libreria Editrice Cafoscariana, pp. 125-148.

SCHEGLOFF, E. (1979). The relevance of syntax for conversation. In: Givon, T. (org.), Syntax and Semantics, Discourse and Syntax. New York: Academic Press, pp. 261-286.

SCHIFFRIN, D. (1992). Discourse: discourse markers. International Encyclopeddia of Linguistics, pp. 361-364.

SINCLAIR, J.M.; COULTHARD, R.M. (1975). Towards an analysis of discourse: the english used by teachers and pupils. London: Oxford University Press.

STAME, S. (1999). I marcatori della conversazione. In: Galatolo, R.; Pallotti, G.; (orgs.), La conversazione: un'introduzione allo studio dell'interazione verbale. Milano: Raffaello Cortina Editore, pp. 169-186.

STAUBER CAPRARA, L. (2003). L'italiano degli italiani di San Paolo alla fine del XX secolo. In: De Fina A.; Bizzoni F. (orgs.), Italiano e italiani fuori d'Italia. Perugia: Guerra Edizioni, pp. 203-205.

SWAIN, M. (1985). Communicative competence: some roles of comprehensible input and comprehensible output in its development. In: Gass, S. M.; Madden, C. G. (orgs.), Input in second language acquisition. Mahwah, NJ: Lawrence Erlbaum, pp. 235- 253. 
URBANO, H. (2006). Marcadores discursivos basicamente interacionais. In: Jubran, C. C. A. S.; Koch, I. G. V. (orgs.), Gramática do português culto falado no Brasil. Campinas: Editora Unicamp, pp. 497-527.

URBANO, H. (1997). Marcadores conversacionais. In: Preti, D. (org.), Análise de textos orais. São Paulo: Editora Humanitas, pp. 81-101.

STAME, S. (1999). I marcatori della conversazione. In: Galatolo, R.; Pallotti, G.; (orgs.), La conversazione: un'introduzione allo studio dell'interazione verbale. Milano: Raffaello Cortina Editore, pp. 169-186.

VAN LIER, L. (1988). The classroom and the language learner. London: Longman.

WATSON-GEGEO, K. (1997). Classroom ethnography. In: Horberger, N.H.; Corson, D., (orgs.), Encyclopedia of language and education, vol. 8, Research Methods in language and Education, The Netherlands, pp. 135-144.

WILLIS, J. (1996). A framework for task-based learning. London: Collins.

Recebido: 12/08/2015

Aceito: 05/11/2015 